\title{
KAJIAN SEBARAN AIR PANAS DI KELURAHAN TOBOLOLO DAN KELURAHAN SULAMADAHA KECAMATAN PULAU TERNATE KOTA TERNATE
}

\author{
Abdul Haris Rajab ${ }^{1}$, Rohima Wahyu Ningrum ${ }^{2}$, Jumaris $^{3}$ \\ ${ }^{1}$ Mahasiswa Program Studi Pendidikan Geografi FKIP Universitas Khairun Ternate \\ ${ }^{2}$ Dosen Program Studi Pendidikan Fisika, FKIP Universitas Khairun Ternate, Email: rohima_wn@yahoo.co.id \\ ${ }^{3}$ Dosen Program Studi Pendidikan Geografi, FKIP Universitas Khairun Ternate
}

\begin{abstract}
Abstrak: Tujuan dari penelitian ini adalah untuk mengetahui potensi panas bumi dan sebaran air panas di sekitar Kelurahan Tobololo dan Kelurahan Sulamadaha, Pulau Ternate bagian utara. Hasil pengukuran magnetik di lapangan haruslah dihitung terlebih dahulu agar bisa mendapatkan anomali magnetik yaitu medan magnet total dikurangi dengan magnet variasi harian, serta dikurangi dengan medan magnet utama bumi(nilai IGRF). Nilai IGRF 40137.7, Nilai medan magnet total yang terbaca pada fluxgate magnetometer sangat bervariasi antara $44907.9 \mathrm{nT}$ s/d $73351.8 \mathrm{nT}$,Total koreksi yang didapat setelah medan magnet total dikurangi magnet variasi harian dan dikurangi nilai IGRF. Nilai anomali magnetik yang didapat setelah nilai magnet total dikurangi dengan nilai total koreksi yaitu berkisar antara $4791.7 \mathrm{nT}$ s/d $33235.9 \mathrm{nT}$. Sebaran suhu airtanah dengan lokasi pengukuran memanjang lebih dari $5 \mathrm{~km}$ dan lebar $1 \mathrm{~km}$ dari bibir pantai hingga ke arah ketinggian dimana sumur gali atau sumur bor masih ditemukan. Suhu airtanah berkisar $26^{\circ} \mathrm{C}-35.5{ }^{\circ} \mathrm{C}$. Suhu air tertinggi hanya terdapat di dua titk mata air, yakni di Desa Tobololo dan Desa Sulamadaha. Ini menunjukkan perbedaan suhu hampir pada semua air sumur.
\end{abstract}

Kata Kunci: air panas, gunung api, magnetik. 


\section{PENDAHULUAN}

Maluku Utara terletak di jalur ring of fire dimana jalur ini adalah jalur keberadaan gunung api. Jalur gunung api menjadi sumber terbentuknya atau berpotensi memiliki energi panas bumi. Energi panasbumi adalah energi sumberdaya alam berupa air panas atau uap yang terbentuk dalam reservoir di dalam bumi melalui pemanasan air bawah permukaan oleh batuan beku panas (Tim Pertamina, 2007). Prospek energi panas bumi sangat menjanjikan sebagai energi alternatif terbarukan, dan penelitian mengenai potensi energi panas bumi masih terus dilakukan sampai sekarang. Maluku utara terdapat beberapa gunung api baik yang masih aktif maupun yang tidak aktif (istirahat), yaitu: Gunung Gamalama, Gunung Dukono, Gunung Gamkonora, Gunung Ibu, Gunung Kie Matubu, dan Gunung Kie Besi.

Energi panas yang terkandung dalam air panas menjadi fenomena alam sejak dahulu kala hingga sekarang namun seiring berjalannya waktu, pengetahuan dan tekhnologi telah banyak membantu manusia untuk lebih jauh mengetahui secara mendalam. Panas bumi tersebut mengalami perpindahan energi dan masuk ke dalam tubuh air yang menyebabkan terjadinya perubahan temperature air. Fenomena ini telah banyak terjadi di sekitar kita dan tentunya hal ini akan menjadi sasaran objek yang menarik untuk dikaji lebih dalam yakni dengan melakukan penelitian. Kenampakan panas bumi juga terdapat di bawah kaki Gamalama yakni di Kelurahan Tobololo dan Kelurahan Sulamadaha Kecamatan Pulau Ternate, Kota Ternate. Daerah yang terletak di Kelurahan Tobololo dan Kelurahan Sulamadaha, Kelurahan Tobololo adalah sebuah daerah tempat pariwisata berupa pantai pesisir yang terletak di Pulau Ternate bagian utara.

Tujuan dari penelitian ini adalah untuk mengetahui potensi panas bumi dan sejauh mana sebaran air panas di sekitar daerah penelitian berdasarkan anomali magnetik.

\section{METODE PENELITIAN}

Secara administratif Kelurahan Tobololo dan Kelurahan Sulamadaha berada di kecamatan Pulau Ternate, Kota Ternate, Provinsi Maluku Utara. Dilihat dari Letak Geografis Kelurahan Tobololo dan kelurahan Sulamadaha berbatasan dengan kelurahan Bula di sebelah timur, berbatasan dengan keluraha Takome di sebelah barat sedangkan sebelah utara terdapat wilayah laut kota Ternate, dan sebelah selatan terdapat perkebunan masyarakat desa tersebut. 


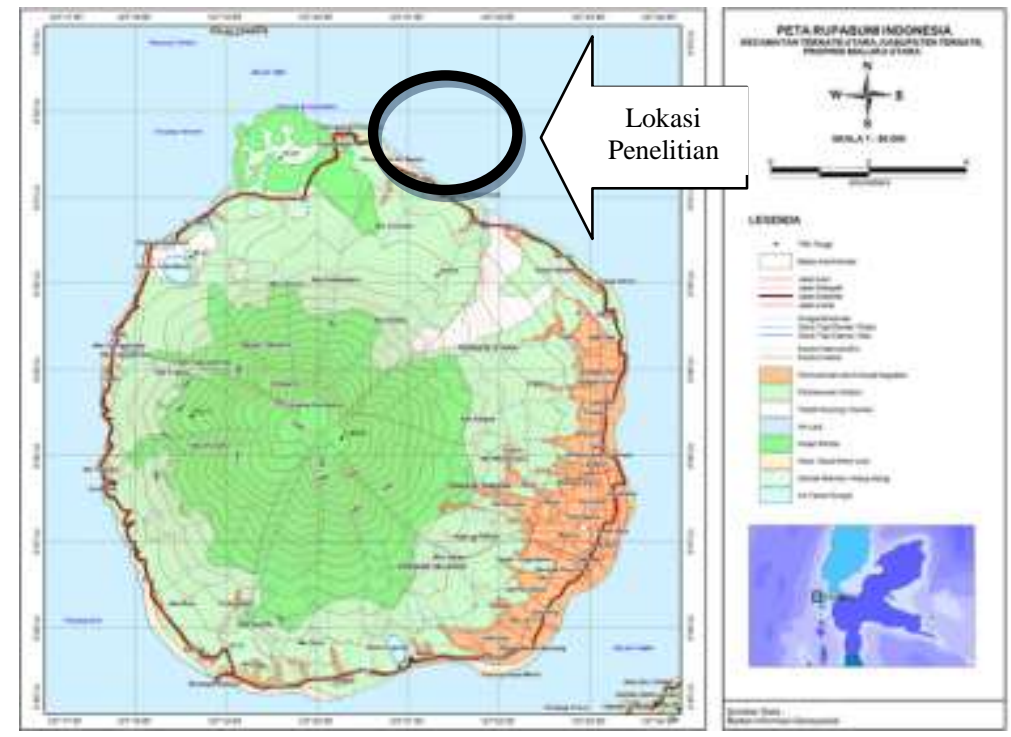

Gambar 1. Peta Lokasi Penelitian

Jenis penelitian yang digunakan adalah penelitian deskriptif kuantitatif.Penelitian deskriptif berkenaan dengan pengumpulan data untuk mendeskripsikan suatu fenomena alam.Di dalam penelitian analisis deskriptif kuantitatif digunakan untuk menjelaskan hasil penelitian berupa angka secara naratif.

Metode yang digunakan dalam penelitian ini adalah salah satu metode geofisika yaitu metode magnetik yang sering digunakan untuk survei pendahuluan pada eksplorasi minyak bumi, gas bumi dan penyelidikan batuan mineral serta untuk mengetahui lapisan batuan. Metode magnetik bekerja sesuai dengan sifat-sifat magnetik batuan yang terdapat di bawah permukaan bumi.Pada perkembangannya, metode magnetik banyak digunakan di berbagai bidang geofisika lainnya termasuk untuk penelitian mengenai gunungapi dan struktur bawah permukaan bumi.

Untuk melakukan pengambilan data dan sampel di lapangan maka alat - alat yang digunakan adalah :
A. Untuk survei lapangan :

- Flux Gate Magnetometer

- GPS Garmin untuk mengetahui kordinat posisi yang nantinya diplot dalam peta

- Rol meter untuk pengukuran ke dalaman muka air tanah dan jarak sumur dari garis pantai

- Jam tangan untuk pencatatan waktu

- Kamera dan handycam untuk dokumentasi lapangan

B. Untuk dasar pemetaan :

- Peta Rupa Bumi Indonesia skala 1 : 25.000

- Peta Geologi Lembar Ternate skala 1 : 25.000

- Peta Topografi skala 1: 25.000

- Peta Penggunaan Lahan skala 1: 25.000

C. Perangkat lunak:

- Software pemetaan Global Mapper 12

- Surfer 11

- Software Argis 9 


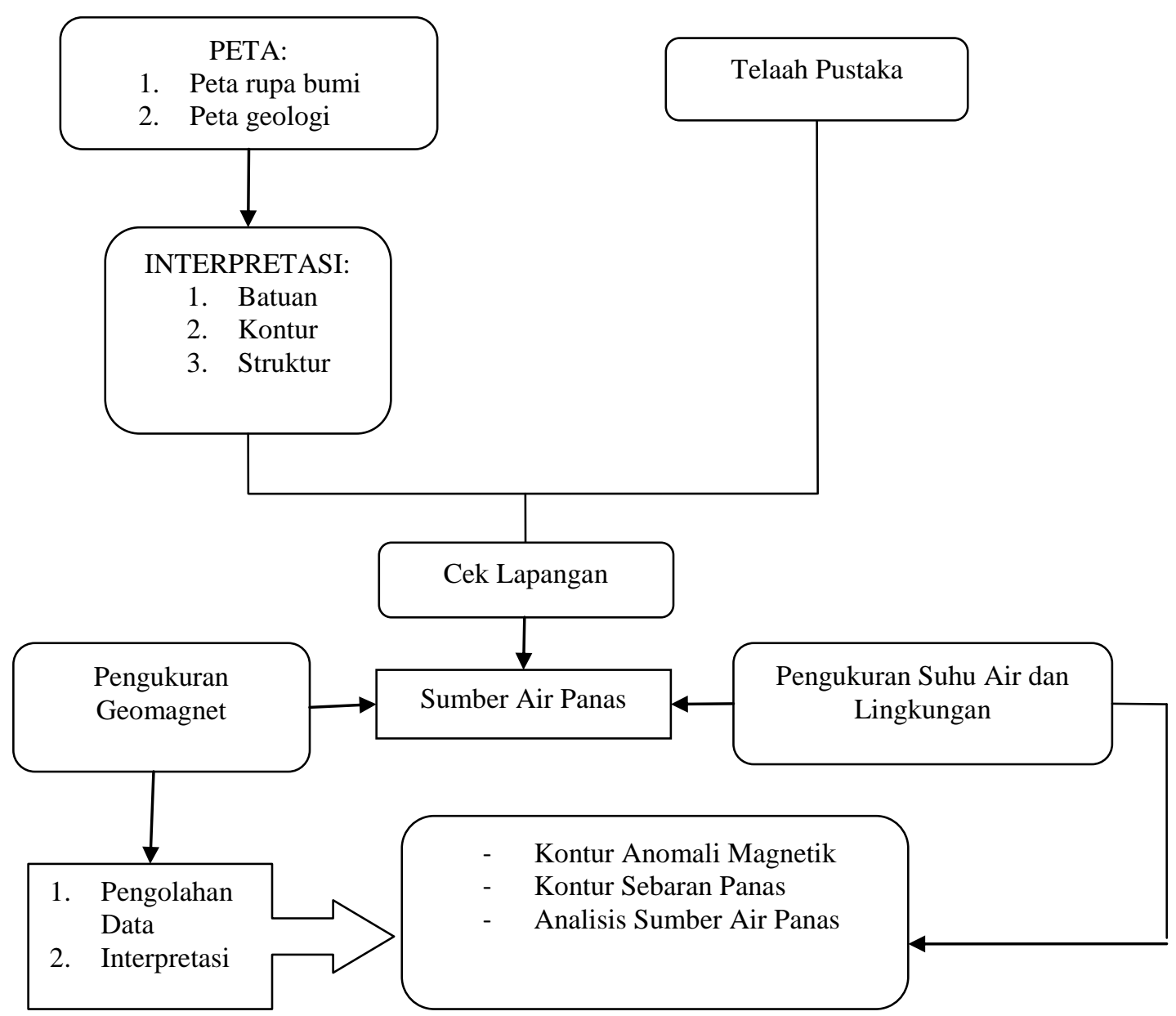

Gambar 2. Diagram Alir Penelitian

\section{HASIL DAN PEMBAHASAN}

Hasil pengukuran magnetik di lapangan haruslah dihitung terlebih dahulu agar bisa mendapatkan anomali magnetik yaitu medan magnet total dikurangi dengan magnet variasi harian, serta dikurangi dengan medan magnet utama bumi(nilai IGRF). Nilai IGRF 40137.7, Nilai medan magnet total yang terbaca pada fluxgate magnetometer sangat bervariasi antara 44907.9 nTs/d 73351.8 nT,Total koreksi yang didapat setelah medan magnet total dikurangi magnet variasi harian dan nilai IGRF yaitu berkisar antara $-21.06 \mathrm{nT}$ s/d $22.27 \mathrm{nT}$. Nilai anomali magnetik yang didapat setelah nilai magnet total dikurangi dengan nilai total koreksiyaitu berkisar antara $4791.7 \mathrm{nT}$ s/d $33235.9 \mathrm{nT}$.

Nilai anomali di atas kemudian dibuat dalam bentuk kontur anomali magnetik dan dioverlay pada peta. Nilai anomali pada peta memperlihatkan nilai anomali kemagnetan batuan yang bervariasi dilihat dari warnanya dan dapat diklasifikasi dalam 3 kelompok warna, yaitu: anomali rendah (warna biru muda, kurang dari -2500 nT); anomali sedang (warna biru muda - hijau, antara $-2500 \mathrm{~s} / \mathrm{d}$ $15000 \mathrm{nT}$ ); dan anomali tinggi (warna kuning - merah tua, lebih dari 15000 nT). Anomali magnetik tinggi pada skala warna 
kuning tuasampai merah dengan nilai lebih dari 15000 nT ditafsirkan sebagai gambaran dari batuan beku atau batuan vulkanik seperti batuan lava andesit yang diperkirakan mempunyai hubungan erat dengan batuan intrusi yang bersifat magnetik sedang sampai tinggi. Berdasarkan tiga kelompok anomali magnet daerah penelitian didominasi oleh nilai anomali magnetik rendah yang tersebar di baratdaya, baratlaut dan di tengah daerah penelitian. Sedangkan anomali magnetik tinggi tersebar di tengah dan timurlaut daerah penelitian dan anomali magnetik sedang terdapat hanya di bagian tenggara dan barat pada daerah penelitian.

Nilai anomali magnet positif diinterpretasikan berhubungan dengan batuan bawah permukaan yang memiliki kerentanan nilai magnet tinggi (Idral, 2005 dan Mustang dkk., 2005) atau batuan yang belum mengalami ubahan.Anomali magnet positif pada penampang anomali geomagnet diperkirakan sebagai batuan diorit yang masih utuh (belum mengalami ubahan). Batuan diorit adalah batuan intermediet yang memiliki nilai susseptibilitas yang relatif tinggi (Idral, 2005). Telford (1990) memberik an nilai 600 - 120.000 (SI) untuk batuan diorit.

Nilai anomali magnet negatif diinterpretasikan sebagai batuan bawah permukaan yang bersifat nonmagnetik ( Idral dkk., 2009 ) atau batuan yang telah mengalami ubahan ( Mustangdkk., 2005 ). Anomali magnet negatif pada pada anomali magnetik diperkirakan sebagai batuan granit dan diorit yang telah mengalami ubahan dan aluvial yang bersifat non magnetik. Granit dan aluvial menurut Idral (2005) memiliki respon magnet yang sangat rendah. Dari empat lintasan yang kami ukur menunjukkan bahwa anomali magnet negatif mendominasi bagian barat laut lintasan.

Sedangkan bagian tenggara lintasan didominasi oleh anomali magnet positif. Bagian barat laut lintasan ditempati oleh batuan intrusi masih utuh dan belum mengalami perubahan sifat fisika.Anomali magnet negatif yang mendominasi bagian barat laut lintasan diperkirakan sebagai batuan granit dan diorit yang atau batuan yang mengalami ubahan. Bagian tenggara lintasan ditempati oleh aluvial. Aluvial yang bersifat nonmagnetik diperkirakan sebagai lapisan permukaan. Respon magnet tinggi pada peta anomali magnetik diperkirakan sebagai batuan yang tidak tersingkap ke permukaan. Anomali positif ini diperkirakan berasal dari batuan batuan yang tidak tersingkap ke permukaan.

Nilai kemagnetan yang bervariasi dan tidak beraturan antara anomali magnet positif dan negatif secara geologi,Menurut Idral (2005), mengindikasikan adanya zona struktur yang komplek di sekitar titik ukur. Nilai kemagnetan yang bervariasi dan tidak beraturan seperti tampak pada peta diperkirakan berkaitan dengan zona kontak litologi ataupun zona sesar. Kontur anomali positif dan negatif yang terjadi pada beberapa titik ukur yang berkisar antara 4791.7 nT s/d 33235.9 nT. nT,

Indikasi struktur geologi dan perbedaan litologi daerah Tobololo dan Sulamadaha pada peta anomali magnetik diperoleh melalui kontur nilai anomali positif dan negatif . Kontur anomali positif dan negatif pada peta anomali magnetik daerah Tobololo dan Sulamadaha $>4791.7$ nT. Struktur geologi pada daerah air panas berfungsi sebagai faktor pengontrol fluida daerah panas bumi 


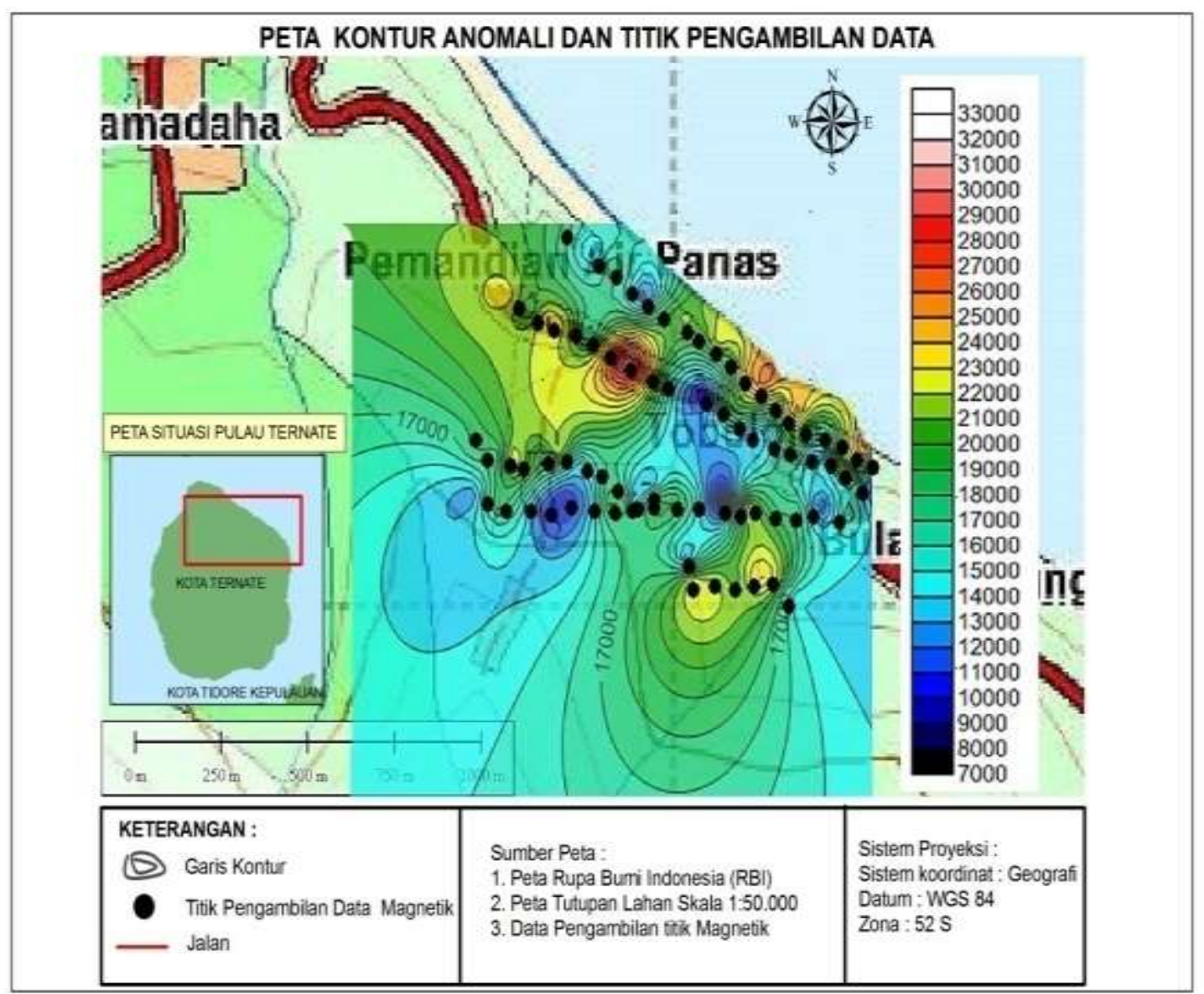

Gambar 3. PetaKontur Anomali dan Titik Pengambilan Data.

Pola warna dan garis yang ditunjukkan dalam peta anomali terlihat adanya Anomali tinggi dan rendah, yang membentuk kutub-kutub magnetik negatif dan positif yang berpola menutup dan terbuka terdapat di bagian pantai yang diinterpretasikan sebagai batuan dengan susseptibilitas sedang sampai tinggi berupa batuanlava andesit-basaltik, bahkan ada yang tersingkap kepermukaan (outcrop).

Anomali magnetik dengan nilai sedang sampai rendah menempati wilayah pantai bahkan hampir semua wilayah pantai lokasi penelitian didominasi oleh anomali tersebut. Hal ini terjadi karena diduga batuan yang terdapat pada daerah tersebut telah mengalami pelapukan kuat atau dipengaruhi oleh sumber panas di sekitarnya, baik itu batuan sedimen ataupun batuan beku.

Hasil pengolahan magnetik ini dapat dibuktikan dengan data Pusat Vulkanologi dan Mitigasi Bencana Geologi Bandung (P3G Bandung), yang menunjukkan ada kemungkinan terjadinya pensesaran pada pulau Ternate yang mengalirkan air panas ke Tobololo dan Sulamadaha kearah pantai.Menurut Idral (2005) serta Idral dan Sumardi (2009) mengindikasikan adanya struktur geologi atau sesar di sekitar titik ukur.Pensesaran ini kemudian akan mengalirkanair melalui celah tersebut dan melewati titik panas yang ada pada sesar, sehingga air yang mengalir akan 
mengalami perubahan suhu sebelum sampai ke Tobololo dan Sulamadaha.Perbedaan harga susseptibilitas yang ditunjukkan pada masing-masing batuan bukan disebabkan oleh perbedaan litologi akan tetapi lebih disebabkan oleh perubahan sifat fisika yang terjadi akibat pensesaran.

Dari kontur peta magnetik (Gambar 4.1) menunjukkan adanya perbedam nilai yangdimungkinkan adanya suatu anomali, pola ini didukung oleh kontur anomali magnetik hasil pengolahan yang menunjukkan kesesuaian dengan posisi sesar dari benda penyebab anomali yaitu di sebelah baratdaya daerah penelitian atau disekitar sumber airpanas Tobololo dan Sulamadaha. Pola kelurusan yang ditunjukkan oleh data P3G Bandung menunjukkan jumlah sesar yang begitu banyak sehingga memungkinkan potensi panas akan keluar dari tempat tersebut. Data magnetik memperlihatkan bahwa adanya benda penyebabanomali yaitu batuan yang memiliki susseptibilitas yang rendah sebagai tanda bahwa batuan daerah sekitar telah mengalami demagnetisasi batuan.

Data magnetik ini mengindikasikan anomali yang tampak hanya kisaran paling rendah $4791.7 \mathrm{nT}$ dan tidak mencapai nilai di bawah 0 atau minus. Pada penelitian yang dilakukan di tempat lain seperti pada penelitian lainnya bahwa rata-rata anomali yang ditemukan sangatlah rendah bahkan mencapai angka $-200 \mathrm{nT}$. Sehingga bisa diduga bahwa penyimpangan (anomali) pada batuan di lokasi sekitarnya masi tergolong anomali kecil.

Informasi geologi yang diperoleh menunjukkan bahwa posisi dari daerah penyebab anomali medanmagnetik tersebut merupakan daerah yang telah tertutupi oleh endapan lahar tua yang memungkinkan batuan telah mengalami perubahan nilai magnetik. Bila mengacu ke informasi geologi daerah penelitian, benda penyebab anomali magnetikini merupakan suatu sesar dan kontak litologi Jadiair panas yang ada di Tobololo dan Sulamadaha ini dikontrol oleh adanya sesar. Dan dimungkinkan air panas yangmuncul dipermukaan berasal dari reservoar panasbumi gunungapi Gamalama yang meresap melalui sesar dan kemudian mengalir lagi ke tempat yang lebih rendah.

Data dari Pusat Penelitian dan Pengembangan Geologi Bandung (P3G Bandung) menjelaskan bahwa terdapat kelurusan (lineament) gunung api berarah timurlaut-baratdaya (NE-SW). Hal ini juga didukung oleh penelitian dari Bronto (1982), menjelaskan tentang keberadaan tiga danau di Pulau Ternate yang posisinya sejajar dengan puncak gunung Gamalama. Ini menunjukkan adanya celah yang memotong pada arah $\mathrm{U} 15^{\circ}-\mathrm{S} 15^{\circ} \mathrm{T}$. Celah ini sejajar dengan rangkaian kepulauan busur di bagian barat Halmahera.

Sesar yang ditemui merupakan sesar turun yang terjadi pada endapan lahar tua dan batas batuan karena merupakan sesar turun maka zona sesar ini kemudian menjadi zona lemah yang mudah untukditerobos, dalam hal ini yaitu air yang berasal dari reservoar panasbumi sehingga di permukaan ditemukan sumber air panas.

\subsection{Zonasi dan Sebaran Air Tanah Pulau Ternate Bagian Utara}

Pengukuran suhu dan tinggi muka airtanah dilakukan bersamaan di sepanjang pesisir pantai lokasi penelitian hingga 
wilayah terjauh menuju daratan/ketinggian dimana sumur gali atau sumur bor masih ditemukan. Pada saat pengambilan data juga dilakukan pengambilan kordinat untuk menentukan kepentingan penentuan lokasi. Suhu air pada setiap sumur galian sangat bervariasi disebabkan oleh pengaruh-pengaruh tertentu.

Kaki gunung api memiliki topografi dan geografi yang khas maka air tanahnya mempunyai karakteristik tersendiri. Kaki gunung api yang tinggi mengakibatkan curah hujan tinggi, fragmen-fragmen gunung api memiliki ruang-ruang yang banyak sehingga mudah menyalurkan airtanah serta memiliki mata air di ujung terras, dan pada dasar aliran lava banyakretakan dan ruang maka air tanah dengan mudah melalui dasar sepanjang lembah tersebut.Keadaan airtanah dipengaruhi oleh bentuk geologi dan pada suhu air di sulamadaha dan tobololo.Namun bentuk lahan dan topografi tidak berpengaruh pada suhu hanya saja berpengaruh pada suhu lingkungan, diketahui bahwa suhu lingkungan pada lokasi penelitian mempengaruhi pada permukaannya saja.Hasil pengukuran ini kemudian di sajikan dalam kontur sebaran suhu air sumur, seperti gambar berikut ini:

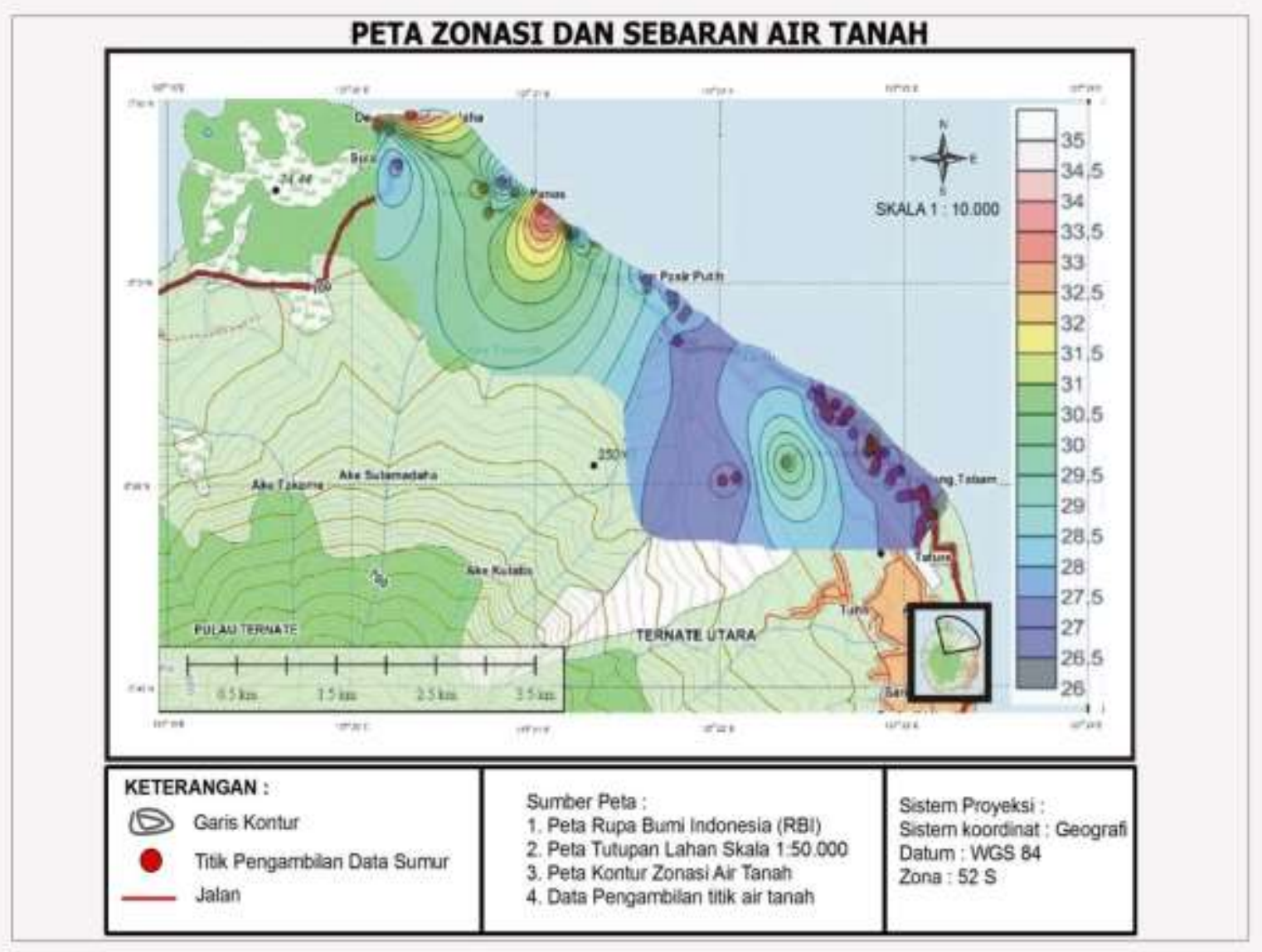

Gambar 4. Peta Zonasi dan sebaran air tanah 
Peta zonasi di atas menggambarkan keadaan sebaran suhu airtanah dengan lokasi pengukuran memanjang lebih dari 5 $\mathrm{km}$ dan lebar $1 \mathrm{~km}$ dari bibir pantai hingga ke arah ketinggian dimana sumur gali atau sumur bor masih ditemukan. Suhu airtanah berkisar $26^{\circ} \mathrm{C}-35.5^{\circ} \mathrm{C}$. Ada 3 klasifikasi suhu, untuk kategori dingin $0^{\circ} \mathrm{C}-28^{\circ} \mathrm{C}$, kategori sedang atau hangat $29^{\circ} \mathrm{C}-40^{\circ} \mathrm{C}$, dan suhu panas yakni $40^{\circ} \mathrm{c}-100^{\circ} \mathrm{c}$. Sebaran suhu ini tidak merata dan terjadi secara diskontinyu. Suhu air tertinggi hanya terdapat di dua titk mata air, yakni di Desa Tobololo dan Desa Sulamadaha. Ini menunjukkan perbedaan suhu hampir pada semua air sumur. Beberapa kilometer sebelum Desa Tobololo suhu air normal dan berangsur-angsur naik.Setelah melewati Desa Tobololo, suhu air berangsur-angsur turun dan kembali naik lagi ketika memasuki Desa Sulamadaha.

Klosur-klosur kelurusan yang diindikasikan sebagai pensesaran yang menjadi penyebab adanya sistem aliran $u p$ flow fluida panas yang masuk ke sistem alir airtanah. Diperkirakan sumber panas atau zona reservoar, hanyalah cabangan dari magma induk, yang merambatkan panas secara konduktif ke batuan dasar (bed rock). Batuan penudung berupa sedimen dan endapan volkanik diatasnya bertindak sebagai lapisan akuifer yang akan meneruskan konduksi panas ke sistem alir airtanah secara konveksi. Keberadaan bidang sesar tentulah menjadi media untuk mengalirkan energi panas (up flow) ke dalam tubuh akuifer.

Peta zonasi dibuat berdasarkan data pengamatan sumur gali penduduk dan sumur bor dalam wilayah peneltian. Secara umum sumur gali penduduk berada di daerah paling rendah di kaki
gunung.Kedalaman muka airtanah mengikuti bentuk topografi gunung. Makin jauh meninggalkan pesisir pantai makin dalam muka airtanah. Begitu juga pada sumur bor yang berada di ketinggian atau yang sudah berada di daerah tubuh gunung.

Dengan mencermati Gambar 4.3, Ini berarti zona reservoir panas tidak berada jauh dari sumber mata air. Artinya, titik sumber panas (heat source) diduga berada di persimpangan kelurusan yang mencabangkan arah alir airtanah, dimana airtanah diarahkan oleh kelurusan sesar menuju pantai, sehingga air panas hanya keluar pada ujung kelurusan (spot tertentu saja). Tempat lain yang airnya bersuhu normal, secara umum tidak terhubung dengan zona reservoir air panas.Secara umum, kenaikan suhu perairan akan mengakibatkan kenaikan aktifitas biologi sehingga akan membentuk $\mathrm{O}^{2}$ lebih banyak lagi. Kenaikan suhu air secara alamiah biasanya disebabkan oleh aktifitas penebangan vegetasi disekitar sumber air tersebut, sehingga menyebabkan banyaknya cahaya matahari yang masuk ke dalam tubuh air tersebut dan mempengaruhi akuifer yang ada secara langsung atau tidak langsung. Namun pada penelitian ini perubahan kenaikan suhu air yang terjadi di lokasi penelitian lebih disebabkan oleh sumber panas yang berasal dari perut bumi.

Diketahui bahwa ada air sumur yang memiliki suhu di atas $30^{\circ} \mathrm{Cdan}$ yang lainnya di bawah $30^{\circ} \mathrm{c}$ dari data yang di peroleh di lapangan. Data B1 $27^{\circ} \mathrm{C}$ dan B2 $28^{\circ} \mathrm{C}$ dan $\mathrm{B} 330^{\circ} \mathrm{C}$. dilihat dari variasi suhu ini menunjukkan adanya factor-faktor yang mempengaruhinya. Data B3 secara tidak langsung dipengaruhi oleh temperature 
dari dalam bumi. Sedangkan B1 dan B2 dipengaruhi oleh suhu yang ada di lingkungan sekitarnya.

Data pada K1-K7 mempunyai suhu rata-rata antara $27^{\circ} \mathrm{C}-28^{\circ} \mathrm{C}$ sehingga bisa diketahui bahwa suhu ini masuk kategori suhu normal air. Data S1-S16 dengan ratarata suhu $26^{\circ} \mathrm{C}-27^{\circ} \mathrm{C}$, bisa diduga bahwa di daerah ini tidak dipengaruhi oleh panas dari dalam bumi dan hanya dipengaruhi oleh suhu lingkungan. Demikian halnya pada data T1-T12 dengan suhu berkisar antara $26^{\circ} \mathrm{C}-27^{\circ} \mathrm{C}$, ini menunjukkan hanya dipengaruhi oleh suhu alam sekitar dan masi dikategorikan sebagai suhu air yang normal.

Berbeda halnya dengan data SU1SU7 yang memiliki suhu yang sangat berbeda dengan kebanyakan air sumur. Suhu untuk SU1 dan SU2 adalah $30^{\circ} \mathrm{C}$ dan suhu untuk SU3 $34^{\circ} \mathrm{C}$, SU4 $32^{\circ} \mathrm{C}$ dan SU5 $30^{\circ} \mathrm{C}$ serta SU6 $29^{\circ} \mathrm{C}$. Dilihat dari suhu tersebut maka bisa diduga perubahan suhu tersebut bukan karena factor lingkungan sekitar akan tetapi lebih dimungkinkan pada pengaruh dari dalam perut bumi. Sebagaimana hasil penelitian pada anomali magnetik yang memperkuat dugaan tersebut. Hasil suhu tersebut juga tidak jauh berbeda dengan data TO. Khusus untuk T4 dengan suhu tertinggi di antara semua data sumur yaitu $35^{\circ} \mathrm{C}$. Data yang lain pada TO $128^{\circ} \mathrm{C}$, TO2 $27^{\circ} \mathrm{C}$, TO3 $29^{\circ} \mathrm{C}$, TO5 $33^{\circ} \mathrm{C}$, TO6 $26^{\circ} \mathrm{C}$, Tobololo $730^{\circ} \mathrm{C}$, dan Tobololo 8-Tobololo $931^{\circ} \mathrm{C}$. Suhu pada daerah ini sangat berbeda antara air sumur satu dengan yang lain, ada beberapa air sumur yang masih dipengaruhi oleh panas dari dalam bumi yaitu pada TO3, TO5, TO7, TO8 dan TO9 dengn suhu ratarata di atas $29^{\circ} \mathrm{C}$ sehingga suhu sumur yang ada pada TO1, TO2 dan TO6 tidak terpengaruh faktor dari dalam bumi hanya saja dipengaruhi faktor alam sekitar.

Suhu yang terkhir adalah TA1TA17 dengan suhu rata-rata $26^{\circ} \mathrm{C}$ dan hanya satu sumur saja yang memiliki suhu $27^{\circ} \mathrm{C}$ yakni data TA3. Semua suhu tersebut hanya dipengaruhi oleh suhu alam sekitar dan tentu tidak dipengaruhi oleh panas dari dalam bumi. Sehingga potensi pada daerah TO dan SU termasuk kategori panas bumi rendah karena dilihat dari suhu yang ditunjukkan oleh air sumur yang masih di bawah $36^{\circ} \mathrm{C}$. Sebagaimana ciri-ciri panas bumi yang diklasifikasikan oleh Abdurahman Oman yaitu temperature rendah $10^{0} \mathrm{C}-92^{\circ} \mathrm{C}$, temperature sedang $92^{\circ} \mathrm{C}-150^{\circ} \mathrm{C}$, temperature tinggi $>150^{\circ} \mathrm{C}$. Sesuai dengan penerapannya di lapangan khususnya suhu di bawah $92^{\circ} \mathrm{C}$ telah digunakan di beberapa Negara maju dengan tekhnologi yang termutakhir saat ini sehingga pemanfaatannya sangat maksimal. Di beberapa Negara berkembang, pemanfaatan panas bumi menggunakan tekhnologi yang sederhana pada suhu di atas $92^{\circ} \mathrm{C}$. Hal ini dikarenakan tekhnologi yang sederhana tidak dapat mengelolah panas bumi dengan temperatur di bawah $92^{\circ} \mathrm{C}$.

\section{SIMPULAN \& SARAN}

\section{Simpulan}

Dari hasil data yang telah dianalisis dan pembahaasan yang telah diuraukan diatas maka dapat disimpulkan sebagai berikut:

1. Sebaran air panas di bagian utara Pulau Ternate menunjukkan terdapat dua titik mata air panas tersebar yang tidak merata. Suhu air sebelum desa Tobolo umumnya normal, kemudian berangsur-angsur naik hingga 
mencapai suhu $35^{\circ} \mathrm{C}$. Tobololo dan Sulamaha hannya memiliki sedikit potensi panas bumi dilihat dari anomali yang didapat yaitu $4791.7 \mathrm{nT}$.

2. Sebaran air panas di Tobololo dan Sulamadahasecara umum darihasil pengukuran suhu airmasih tergolong panas bumi dengan akuifer temperatur rendah.

\section{Saran}

1. Saran kami kepada pemerintah kota Ternate agarmenjadikan daerah Tobololo dan Sulamadah sebagai pusat kajian geologi karena daerah ini memiliki strukrur geologi yang komplek.

2. Saran kepada masyarakat Tobololo dan Sulamadaha agar lebih menjaga kebersihan sekitar sumur-sumur agar terlihat lebih indah dan tidak tercemar oleh sampah-sampah.

\section{DAFTAR PUSTAKA}

BAPPEDA. 2014. Laporan Revisi Rencana Tata Ruang Wilayah. (RTRW) Kota Ternate 2011-2031

Bronto, S.Hadisantoso RD, dan Lockwood, JP, 1982.Peta Geologi Gunungapi Gamalma, Ternate Maluku Utara, Direktorat Volkanikologi, Bandung.

Broto, S., Putranto, T.T., 2011, “Aplikasi Metode Geomagnet Dalam Eksplorasi Panas Bumi”. Jurusan Teknik Geologi Fakultas Teknik Undip.

Dobrin, M.B. and Savit, C.H., 1988. "Introduction to Geophysical Prospecting”, New York: McGraw-Hill Book Company.
Idral, A. 2005.Hasil Penyelidikan Geomagnit Daerah Panas Bumi Suwawa Kab. Bone Bolango Propinsi Gorontalo. Makalah disajikan dalam Kolokium Direktorat Inventarisasi Sumber Daya Mineral 2005, Pusat Sumber Daya Geologi Badan Geologi.

Idral, A. \& Sumardi, E. 2009. Hasil Penyelidikan Geomagnetik Daerah Panas Bumi Bittuang Kabupaten Tana Toraja-Propinsi Sulawesi Selatan. Makalah disajikan dalam Kolokium Badan Geologi 2009, Pusat Sumber Daya Geologi Badan Geologi.

Indratmoko, P., M. Nurwidyanto, I., Yulianto T, 2009. "Interpretasi Bawah Permukaan Daerah Manifestasi Panas Bumi Parang Tritis Kabupaten Bantul DIY Dengan Metode Magnetik” Jurusan Fisika FMIPA UNDIP Semarang.

Katili, J.A., 1973. Volcanism and Plate Tectonics in the Indonesia Island Arcs, Tectonographysics, 165-188.

Nuha, Dafiqiy ya'lu ulin.2012.Pemodelan Struktur Bawah Permukaan Daerah Sumber Air Panas Songgoriti Kota Batu Berdasarkan Data Geomagnetik. Jurusan Fisika, Fakultas Sains dan Teknologi UIN Maliki Malang.

Mustang, A. Sumardi, E. \& Budiraharja. 2005. Survei Geomagnet di Daerah Jaboi, Kota Sabang, Daerah Istimewa Aceh. Makalah disajikan dalam Kolokium Badan Geologi 2005, Pusat Sumber Daya Geologi Badan Geologi. 
Oman, A,2010. Negeri 1001 Bencana.

Pusat Penelitian dan Pengembangan

Geologi Bandung (P3G Bandung).

Sharma,P.V., 1997. Environmental and

Engineering Geophysics,

Cambridge University Press,

United Kingdom.

Telford, Geldart and Sheriff. 1990. Applied

Geophysics. Cambridge University

Press

Telford, W.M., L.P. Geldart, and R.E.

Sheriff, 1998.Applied Geophysics, 2nd ed.,Cambridge University Press, New York.

Telford, W.M ., Geldart, L.P . \& Sheriff, R.E. (1990). Applied Geophysics. Cambridge : Cambridge University Press

Telford, W.M. 1976. Applied Geophysic. Cambridge University Press: Cambridge.

Tim pertamina. 2007. Peluang pemanfaatan potensi energi geothermal ulubelu lampung. Makalah workshop geofisika universitas lampung. Bandar lampungs

Untung, M. 2001. Dasar-Dasar Magnet Dan Gaya Berat Serta Beberapa Penerapannya. Himpunan Ahli geofisika Indonesia (H.A.G.I). Jakarta. 